\title{
Penubuhan mimer dalam proses kreatif pertunjukan pantomim
}

\section{Embodiment of mimer in creative process of pantomim performance}

\author{
Dwi Febrianto \\ Program Studi Antropologi, FIB, Universitas Brawijaya, Malang \\ Jalan Veteran Malang, Kota Malang, Jawa Timur 65145, Indonesia. \\ Telepon: +62 341575875 \\ E-mail: dwifebrianto69@gmail.com
}

\begin{abstract}
Pantomime is a show that relies to actor's body movement and facial expression. The question proposed in this research is how the mime actor's creative process related to body movement's usage in a pantomime show? Researcher conducted the research by phenomenological approach. Targeted informants are 1) Theater community Sendratasik coach and Lecturer form UNESA; 2) Head of Sendratasik theater UNESA; 3) Show's director; 4) mime actors; 5) active member of Sendratasik theater. This research concludes that in order to reach total appreciation to the role, a mime actor practiced various activites long before the performance day. These activites include joint practice or personal appreciation beyond the practice time. Mime actor's personal experience is an important thing for actor to play the role. Religious experiences also influence training session or mime actor's effort in understanding the role. This is suitable with embodiement function which performed personally or communally by mime actor(s).
\end{abstract}

Keywords: pantomime, mime actor, embodiment, creative process

\begin{abstract}
Abstrak
Pantomim merupakan pertunjukan yang mengandalkan gerak tubuh aktor dan mimik wajah aktor. Bagaimana proses kreatif aktor yang berkaitan dengan penggunaan tubuh dalam pertunjukan pantomim? Peneliti melaksanakan penelitian ini dengan menggunakan suatu metode atau pendekatan fenomenologi. Beberapa sasaran yang menjadi informan penelitian adalah, 1) Pembina komunitas Teater Sendratasik dan Dosen, FBS UNESA; 2) Ketua Umum komunitas Teater Sendratasik, FBS UNESA; 3) Sutradara Pertunjukan; 4) Para Pemain; 5) Beberapa anggota aktif komunitas Teater Sendratasik (2-5 orang). Dapat disimpulkan bahwa untuk mencapai suatu taraf penghayatan yang total, pemain pantomim (mimer) melakukan berbagai latihan dan kegiatan yang dilakukan jauh-jauh hari sebelum acara berlangsung. Kegiatan-kegiatan tersebut termasuk latihan yang dilakukan bersama-sama, maupun penghayatan pribadi yang dilakukan di luar jam latihan. Pengalaman pribadi mimer adalah termasuk hal yang dimanfaatkan untuk penghayatan. Kepercayaan (pengalaman religius) juga mewarnai praktek yang diberlakukan oleh pelatih, maupun usaha penghayatan yang dilakukan oleh aktor pantomim. Hal ini sesuai dengan fungsi embodiment yang dilakukan secara personal maupun komunal.
\end{abstract}

Kata kunci: pantomim, mimer, penubuhan, penghayatan, proses kreatif

\section{Pendahuluan}

Negara berkembang seperti Indonesia mendapatkan banyak pengaruh dari luar, khususnya dalam perkembangan seni pertunjukannya (Soedarsono 1998). Salah satu bentuk seni pertunjukannya adalah teater. Seni pertunjukan teater di Indonesia bermula pada masa penjajahan Belanda (Iswantara 2004: 66). Ada teater tradisional (berasal dari rakyat dan lebih banyak improvisasi) yang memiliki tiga bentuk menurut Kasim Ahmad (1981 dalam Suhariyadi 2014) yaitu teater rakyat, teater klasik dan teater transisi. Sedangkan bentuk lain dari perkembangan teater di Indonesia adalah teater modern di Indonesia. Perkembangan teater modern ini melahirkan tokoh- 
tokoh teater mulai dari Sanusi Pane (era 1940-an) sampai dengan W.S Rendra (era 1990-an). Tokoh-tokoh inilah yang juga mempengaruhi perkembangan seni pertunjuka teater di Indonesia. Salah satu wujud pertunjukan yang sudah lama ada dan menggunakan gerak tubuh sebagai media menyampaikan pesan adalah pantomim. Pantomim merupakan pertunjukan yang mengandalkan gerak tubuh aktor dan mimik wajah aktor. Tokoh pantomim dunia yang terkenal adalah Marcell Marceau dan Charlie Chaplin yang juga mempelopori aktor film bisu. Jika di Eropa memiliki Marcell Marceau atau Charlie Chaplin di Indonesia ada Jemek Supardi yang juga maestro pantomim Indonesia. komunitas Teater Sendratasik FBS (Fakultas Bahasa dan Sastra) UNESA sering menonjolkan pertunjukan yang mengedepankan tubuh sebagai dialog kepada para penonton. Namun pantomim tetap menjadi bekal bagi anggota komunitas Teater Sendratasik untuk menjadi aktor. Dua hal yang ingin dikaitkan peneliti adalah proses tubuh mengalami pengalaman-pengalaman yang dirasakan langsung serta imajinasi pikiran yang dituangkan melalui gerak tubuh dalam pertunjukan pantomim Beauty and The Beast di komunitas Teater Sendratasik. Pertanyaan yang muncul adalah, bagaimana proses kreatif aktor yang berkaitan dengan penggunaan tubuh dalam pertunjukan pantomim?

\section{Metode Penelitian}

Disiplin ilmu filsafat yang digunakan adalah pendekatan fenomenologi. Tulisannya menjabarkan tentang pengalaman sebagai bentuk untuk memperoleh pengetahuan yang menyediakan dasar rasional. Deskripsi dari penelitian ini lebih fokus pada representasi tekstual dari pergerakan manusia yang menjelaskan tentang studi tari yang dilihat secara budaya. Penelitian ini menjelaskan tentang deskripsi dari gerakan manusia sebagai indikator untuk memahami pergerakan. Untuk memperjelas deskripsinya, penelitian ini mengarah pada bentuk observasi partisipasi untuk memahami proses perwujudan gerakan dalam tari.

Peneliti melaksanakan penelitian ini dengan menggunakan suatu metode atau pendekatan fenomenologi. Metode penelitian secara fenomenologi ini dibangun dari para pemikiran filosofis para filsuf seperti Heidegger, Husserl, dan Maurice Marleu-Ponty. Metode penelitian fenomenologi lebih mengedepankan pengalaman (Simatupang 2013: 79).

Fenomenologi merupakan serapan dari kata phenomenology yang berakar dari phenomenon (tunggal, phenomena - jamak) yang berarti kejadian, perwujudan, gejala (Simatupang 2013: 74). Jenis penelitian ini adalah deskriptif, yaitu peneliti berusaha memberikan gambaran jelas tentang keadaan, gejala, pengalaman dalam sebuah komunitas seni pertunjukan teater. Selain menggambarkan dengan jelas, peneliti juga ingin menceritakan ulang beberapa pengalaman yang menyangkut aspek ketubuhan para anggota komunitas tersebut. Hanya pengalaman yang menyangkut aspek ketubuhan saja yang akan peneliti ceritakan. Hal ini terkait dengan pendekatan fenomenologi yang peneliti gunakan.

Lokasi penelitian adalah di Surabaya. Ini karena gema seni pertunjukan teater masih terdengar raungannya. Gedung Cak Durassim adalah wujud kepedulian pemerintah kota Surabaya terhadap perkembangan seni pertunjukan di Indonesia. Bentuk kegiatan berteater di Kota Pahlawan ini masih terasa atmosfernya. Letak lokasi penelitian di Universitas Negeri Surabaya yang memiliki Fakultas Bahasa dan Sastra dengan salah satu Program Studi Sendratasik (Seni, Drama, Tari, dan Musik).

Beberapa sasaran yang sekiranya akan menjadi informan penelitian nanti adalah, 1) Pembina komunitas Teater Sendratasik dan Dosen, FBS UNESA. Wawancara tentang seluk beluk batasan kegiatan pertunjukan yang dilakukan komunitas Teater Sendratasik dan Sejarah komunitas Teater 
Sendratasik; 2) Ketua Umum komunitas Teater Sendratasik, FBS UNESA. Wawancara tentang bentuk organisasi komunitas Teater Sendratasik. Kegiatan yang dilaksanakan selama satu tahun. Bentuk-bentuk pertunjukan yang dilakukan oleh komunitas Teater Sendratasik; 3) Sutradara Pertunjukan. Wawancara perihal pemilihan naskah, interpretasi naskah, proses pembacaan naskah, pemilihan aktor, proses kreatif yang akan dilakukan menuju pertunjukan/pementasan; 4) Para Pemain yang turut serta dalam proses pertunjukan. Wawancara tentang pengalaman ketubuhan yang membentuk aktor selama proses kreatif. 5) Beberapa anggota aktif komunitas Teater Sendratasik (2-5 orang). Wawancara terhadap pengalaman anggota komunitas lain dalam proses kreatif yang pernah dialami. Wawancara ini dilakukan sebagai data penunjang penelitian. Selama kegiatan pengamatan ini, peneliti berusaha berinteraksi dan membina hubungan baik dengan informan yang bertujuan untuk mendapatkan data secara jelas dan cermat serta akurat berdasarkan apa yang peneliti lihat dan rasakan. Dengan kata lain, data didapat dari pengamatan dan wawancara.

Analisa yang digunakan dari Wainwright dan Turner dalam tulisannya adalah konsep habitus dari Pierre Bourdieu. Habitus bisa didefinisikan sebagai etitud, pergantian posisi, dan rasa berbagi kebersamaan antar individu. Rasa yang dimaksud mengacu pada posisi sosial, praktek dan isntitusi. Dalam teorinya, Bourdieu mengatakan bahwa habitus dan embodiment saling berkaitan. Bourdieu menuliskan bahwa cara seseorang memperlakukan tubuh mereka muncul dari kebiasaan mereka yang terdalam (Bourdieu 1984: 190 dalam Wainwright dan Turner 2004). Analisa yang akan peneliti gunakan dalam penelitian nanti yaitu tentang penubuhan yang sudah dijelaskan dan praktek dramaturgikal tubuh Erving Goffman dalam proses kreatif aktor dibalik sebuah pertunjukan pantomim. Proses kreatif yang dimaksudkan itu adalah melatih tubuh aktor agar bisa mengesankan orang lain/penonton dengan tubuhnya.

Untuk menjelaskan kerja dari perwujudan (embodiment) Allen Ness menganalisanya dengan konsep Radcliffe Brown. Dia berfokus pada merasakan pengalaman dari proses pergerakan yang bisa dilihat bentuk visualnya. Konsep tersebut memiliki hubungan antara rancangan gerakan, pengalaman yang diproduksi dan kemampuan merasakan pengalaman dan pemahaman kultural (Allen Ness 2004).

Penelitian ini melihat kerja berulang-ulang dalam latihan untuk membentuk gestur pemain opera. Selain gestur, pemain opera juga harus memiliki suara yang bagus agar bisa menampilkan performanya secara visual dan musikal. Kata-kata, musik dan tubuh dibawa dalam konjungsi dan tubuh dilatih untuk bergerak serta berintraksi dalam ruang fisik di panggung. Analisa yang digunakan adalah di dalam dunia pertunjukan, terdapat relasi antara penubuhan gestur, intensitas dan motivasi, emosi dan reaksi serta karakter dan aksi. Kerangka teori yang digunakan adalah pemikiran dari Paul Atkinson dan Waskull dan Vanini tentang tubuh dramaturgi yang diadopsi dari konsep Erving Goffman.

\section{Hasil Penelitian dan Pembahasan}

\section{Pembentukan keaktoran pantomim beauty and the beast}

Dijelaskan dengan detail tentang perbedaan penelitian ini dengan penelitian Atkinson (2006).Untuk melatih tubuh para aktor maka dilakukan beberapa latihan rutin. Latihan-latihan yang dilakukan ini berusaha untuk membentuk tubuh agar terbiasa dengan gerak-gerak pantomim. Ada beberapa hal yang ditonjolkan dalam pertunjukan pantomim ini yaitu latihan ekspresi wajah, gerak tubuh, penghayatan, latihan otot, persendian, membentuk tenaga atau power. Untuk melatih gerak-gerak pantomim latihan yang dilakukan adalah cara berjalan pantomim atau istilah umumnya adalah moonwalk. Kelenturan otot leher juga diperlukan karena 
gerak tubuh dapat terbaca dengan jelas ketika mengontrol gerak otot yang ada di tubuh. Adanya latihan di dalam ruang gelap dan tertutup itu bisa membuat para aktor lebih fokus dan menghayati segala bentuk latihan yang diberikan.

Alasan aktor utama memberikan pelatihan di dalam ruangan gelap ini ternyata terkait dengan pengalaman masa lalunya ketika dia sedang melakukan ibadah sholat. Menurut pengakuannya dia ketika kecil diajarkan oleh orang tuanya untuk mematikan lampu ketika sholat agar lebih khusyuk. Pengalaman masa lalu dari aktor utama inilah yang coba dia terapkan kedalam bentuk latihan untuk para aktor lainnya.

"Alasannya mungkin, kalo menurut saya, kembali ketika orang ibadah. Ketika ibadah kebiasaan saya, saya yang selaku praktisi beberapa metode dari tokohtokoh pantomim saya mengaplikasikan. Ketika saya ibadah waktu kecil diajarkan sama orang tua matikan lampu supaya lebih khusyuk. Dadi dimensinya lebih dalam lebih luas, jadi ketika kita memandang lebih fokus. Lek peteng luwih fokus." (Haqi 13 Juli 2015)

Pernafasan adalah kunci manusia hidup di dunia ini. Begitu pula dengan seorang aktor pantomim, dalam pertunjukan ini mengatur pernafasan sangatlah penting agar tenaga yang dikeluarkan dapat terjaga dan teratur. Udara yang kita hirup lewat hidung dan dikeluarkan lewat mulutpun tidak tergesa-gesa. Ketika seorang aktor dapat mengatur pernafasannya maka gerak tubuh yang dilakukan akan terlihat lebih yakin dan berisi (berpower). Kunci utama ketika melakukan latihan pernafasan adalah tatapan mata yang fokus, dada sedikit dibusungkan, tangan berada di depan dada dengan sedikit melengkung, kaki tegak lurus. Setelah siap, latihan dapat dimulai dengan mengambil nafas dari hidung, lalu disimpan di dalam perut, ditahan sambil salah satu kaki diangkat dengan posisi point dan tubuh digerakkan naik turun sekitar $5-8$ hitungan, kaki diturunkan pelan sambil nafas dibuang pelan-pelan.

Pantomim adalah sebuah pertunjukan yang mengandalkan gerak tubuh dalam menyampaikan ekspresi pemain serta cerita. Jadi tubuh adalah modal utama dari seorang aktor pantomim untuk dapat berekspresi. Jadi seorang aktor pantomim harus dapat menggambarkan segala sesuatu (baik benda atau situasi) dengan gerak tubuhnya. Ilusi yang bekerja dalam sebuah pertunjukan pantomim ini adalah benda atau suasana yang digambarkan oleh aktor tersebut. Seorang aktor dapat menciptakan segala bentuk benda atau suasana yang berkaitan dengan cerita menggunakan gerak tubuhnya.

Ketika seorang aktor dapat membuat ilusi tentu dia dapat menciptakan dunia imajinasi ke dalam panggung melalui pikiran aktor dan ditangkap oleh penonton. Sesuai dengan kutipan pernyataan di bawah ini,

"Jadi kuasai tubuh kan di keaktoran saya kan menggunakan 3 poin. Tubuh, ilusi dan penciptaan dunia. Kalau tubuh itu yang dibanyakkan itu ya di bagian-bagian tubuh, koordinasi tubuh. Ilusi, imajinasi, imajinasi ketika sudah masuk ekspresi ilusi ini. Penciptaan dunia, objek itu, respon objek, penciptaan ruang, penciptaan gerak yang membentuk ruang, terus penciptaan ekspresi yang membentuk adegan cerita, ekspresi tok belum tubuhnya." (Haqi 4 Juni 2015)

Untuk melatih ketiga poin di atas perlu dilakukan latihan yang intens. Latihan yang intens ini dimaksudkan agar menjaga fokus. Salah satu bentuk latihan untuk menciptakan ilusi dan penciptaan dunia adalah ketika berlatih menarik tali namun tali tersebut hanya ada di dalam imajinasi para aktor. Ketika mengikuti alur tali tersebut mata sambil terpejam. Fungsi dari memejamkan mata ini adalah untuk melatih fokus dan pikiran agar hanya tertuju pada tali. Dari 
situ peneliti dapat merasakan bahwa aktor secara sadar menciptakan dunia imajinasinya ketika menutup mata sambil berjalan mengikuti alur tali.

\section{Penguasaan ruang}

Ruang bisa berupa imajinasi atau bentuk ruang secara fisik misalkan gedung pertunjukan, panggung atau semacamnya. Salah satu poin yang harus dikuasai oleh seorang aktor adalah ruang. Aktor harus dapat menguasai ruang secara fisik ataupun imajinasi.

\section{Teater kamar: Satu bentuk latihan sampai halusinasi}

Ruang menjadi sebuah media yang dapat membatasi atau bahkan meningkatkan potensi diri. Salah satu bentuk ruang adalah kamar. Kamar biasanya menjadi sebuah ruang privasi bagi setiap individu. Namun untuk Haqi, kamar menjadi sebuah ruang pertunjukan sekaligus latihan baginya. Kamar dia anggap sebagai ruang untuk melatih tubuhnya agar siap berpantomim. Istilah yang digunakan adalah teater kamar karena dia melakukan latihan dan pertunjukan sederhana di kamarnya setiap kali dia selesai kegiatan di kampus.

Latihan pantomim di dalam kamar bisa melatih tubuh agar siap berpantomim dengan melakukan pertunjukan teater kamar. Bahkan sampai seringnya latihan pantomim di kamar, Haqi pernah tertidur dengan masih berbalur make up pantomim.

\section{Penghayatan peran}

Dalam pengamatan peneliti menjelang pertunjukan "Beauty and the Beast", aktor melakukan halhal yang dapat menambah penghayatan. Salah satu yang dilakukan adalah tidak memotong rambut, dan tidak mencucinya selama beberapa lama. Menurut pengakuannya, selama proses pertunjukan pantomim Beauty and The Beast ini dia tidak pernah memotong rambut dan tidak keramas menggunakan shampoo. Selama ini dia hanya merapikan rambutnya dengan tangan dan tidak menyisirnya menggunakan alat bantu sisir. Hal ini dilakukan hanya untuk mendapatkan penghayatan sebagai seorang manusia singa dan rambut yang kusut seperti singa, meskipun pada performance puncaknya tetap dibantu dengan wig.

Aktor utama dalam pertunjukan pantomim Beauty and the Beast ini memiliki beberapa pengalaman - pengalaman yang mendukung eksplorasinya untuk pendalaman karakter. Salah satu pengalamannya juga diterapkan dalam bentuk latihan penghayatan supaya aktor lainnya dapat menghayati peran mereka dan suasana panggung nanti. Selama dia berproses kesenian di komunitas teater sendratasik banyak pengalaman-pengalaman yang telah dilalui salah satu di antaranya adalah latihan teater kamar, sampai berhalusinasi melihat wajah orang di sekitarnya bermake up pantomim.

Tiada gedung pementasan, ruang kamar pun jadi. Mungkin pepatah itulah yang digunakan Haqi ketika dia melakukan latihan pantomim dan menjadi kamar sebagai ruang eksplorasinya. Di dalam kamarnya dia pun bebas berekspresi dan bereksplorasi gerak ataupun make up pantomim.

\section{Patah hati: Pemicu semangat berkegiatan seni}

Haqi sebagai aktor utama dalam pertunjukan pantomim Beauty and the Beast ini. Sebagai seorang aktor utama dalam pertunjukan ini Haqi melihat aktor-aktor lain yang juga pernah merasakan cinta. Cinta dan patah hati letaknya berdekatan dengan perasaan manusia. Ketika Haqi sebagai 
seorang aktor berpikir bahwa dari pengalaman tentang cinta dan patah hatinya bisa membentuk olah rasa karakter beast dalam tubuhnya.

Cinta bisa dirasakan oleh Haqi sebagai pengalaman yang rumit dan campur aduk. Cerita cinta dan pantomim menurut Haqi letaknya saling berdekatan dan identik. Olah rasa dalam cerita cinta pun lebih banyak seperti rasa gembira, sedih, rasa marah, meninggalkan, mengacuhkan, dia mendekat kita menjauh, kita mendekat dia menjauh, dia yang berharap kita mengacuhkan ataupun sebaliknya. Rasa yang diolah dalam cerita cinta lebih kompleks dan cenderung rumit namun sebagian besar orang tahu dan bisa membacanya.

Ingatan rasa tentang patah hati menjadi eksplorasi penghayatan karakter Beast ketika cintanya ditolak oleh Belle. Patah hati menjadi pengalaman yang membekas bagi Haqi karena dia mengalaminya langsung melalui tubuhnya.

\section{Olah rasa di luar latihan}

Latihan tidak hanya dilakukan ketika semua aktor dan sutradara berkumpul. Bentuk latihan lain yang bisa dilakukan diluar jam latihan tetap adalah olah rasa masing-masing di dalam diri aktor. Setiap manusia pernah mengalami rasa bahagia, marah, sedih dan berbagai emosi lainnya. Berbagai emosi yang tentu pernah dialami manusia inilah diharapkan bisa menjadi tabungan eksplorasi olah rasa bagi para aktor.

"Ketika ada masalah, mungkin anak-anak mencoba berekplorasi. Ketika ada maslaah, oh rasane koyok ngene cah-cah. Oh, dadi rasane ngene to? Dadi koyok naskah kae pusinge koyok ngene podo ae. Tak gawe pusinge sing iki. Mungkin akan mengerti. Jadi tabungan eksplorasinya bukan hanya dilatihan saja."

Seorang aktor mengalami berbagai emosi dan rasa yang dialaminya dalam kehidupan sehari-hari. Berbagai emosi yang pernah dialami tersebut tentu akan melekat dalam ingatan. Ketika di dalam panggung pertunjukan seorang aktor membutuhkan emosi marah, bahagia atau kebingungan maka ingatan tersebut akan muncul perlahan atau bahkan cepat dan dimunculkan dalam bentuk gerak, gesture, atau ekspresi wajahnya. Aktor bisa bereksplorasi gerak, gesture atau bahkan emosi karakternya tidak hanya dalam latihan saja.

Contohnya adalah ketika Haqi dalam kehidupan sehari-harinya dikenal ramah dan penuh keceriaan, berubah menjadi kasar. Hal ini dirasakan oleh teman seangkatan kuliahnya yang menjadi aktor juga dalam pertunjukan pantomim ini yaitu Tata dan Nike. Mereka berdua mengatakan bahwa Haqi sedikit kasar dalam berkata dan tindakannya. Perilaku Haqi yang pendiam, riang dan suka membuat kelucuan sedikit mulai berubah ketika proses penggarapan pertunjukan pantomim Beauty and The Beast. Namun disisi lain Haqi pernah bercerita bahwa sikapnya yang kasar dan cuek merupakan bentuk latihan pendalaman karakter Beast yang coba dia terapkan dalam kehidupan sehari-hari. Sehingga karakter Beast bisa dia latih setiap saat, tidak hanya ketika latihan bersama aktor yang lain.

\section{Meditasi}

Meditasi adalah salah satu bentuk latihan keaktoran di teater. Haqi pernah melakukan latihan meditasi ketika dia sedang ada pentas di Kabupaten Blitar bersama semua anggota komunitas Teater Sendratasik. Dalam meditasinya itu dia niatkan untuk mendalami karakter Beast. Lalu dia memejamkan mata dan berusaha berkonsentrasi untuk mendapatkan karakter Beast dengan mencoba merasakan kekuatan magis di luar tubuhnya. Di dalam kepercayaan masyarakat jawa, hal seperti ini dapat terjadi pada seorang individu, di mana spirit atau ruh dari makhluk lain dapat 
masuk ke dalam tubuh individu. Maka ketika dia membuka mata ada salah seorang temannya yang melihat Haqi sampai ketakutan karena melihat matanya Haqi berwarna merah.

Beberapa bentuk latihan fisik yang dilakukan ketika latihan akan membekali seorang mimer berakting di atas panggung. Proses latihan pikiranpun akan membiasakan mimer dalam berimajinasi di atas panggung dan memudahkan memicu ingatan emosi yang akan dimunculkan ke dalam bentuk ekspresi wajah dan gesture tubuh mimer. Peneliti melihat adanya hubungan antara tubuh dan pikiran dalam bentuk gesture yang akan menciptakan ilusi di atas panggung. Tubuh merupakan pembentuk ilusi yang ada di dalam pikiran melalui gesture seorang atau beberapa mimer. Peneliti tidak membahas jauh tentang ilusi yang diciptakan di atas panggung karena pembahasan akan terlalu melebar. Untuk penjelasan tentang ilusi yang diciptakan di atas panggung bisa menjadi saran untuk penelitian lain yang mungkin tertarik dengan pertunjukan pantomim.

Dua poin di atas merupakan bentuk dari yang dinamakan embodiment. Embodiment menurut analisa dan tafsiran peneliti adalah salah satu bentuk dari kerja proses kreatif seorang mimer. Dua poin di atas dianalisis menggunakan teori milik Erving Goffman tentang dramaturgikal tubuh dalam bukunya Waskul dan Vanini (2011). Ada dua poin yang ditekankan dalam analisa dramaturgikal tubuh milik Erving Goffman. Pertama, menekankan bahwa orang-orang selalu membutuhkan wadah untuk mengekspresikan diri dan mengesankan orang lain. Kedua, dramaturgikal tubuh difungsikan untuk memahami secara emosional melalui ritual dramatis secara personal atau komunal. Analisa dramaturgikal tubuh yang pertama menjelaskan tentang fungsi dari embodiment yang dilakukan oleh mimer. Analisis kedua menjelaskan tentang cara melakukan proses embodiment yang bisa dilakukan secara personal atau komunal. Proses latihan yang panjang dan intensif tersebut, peneliti menganalisa serta menafsirkannya ke dalam sebuah istilah embodiment atau sebagai bentuk embodiment aktor pantomim (mimer).

\section{Simpulan}

Dapat disimpulkan bahwa untuk mencapai suatu taraf penghayatan yang total, pemain pantomim (mimer) melakukan berbagai latihan dan kegiatan yang dilakukan jauh-jauh hari sebelum acara berlangsung. Kegiatan-kegiatan tersebut termasuk latihan yang dilakukan bersama-sama, maupun penghayatan pribadi yang dilakukan di luar jam latihan. Pengalaman pribadi mimer adalah termasuk hal yang dimanfaatkan untuk penghayatan. Kepercayaan (pengalaman religius) juga mewarnai praktek yang diberlakukan oleh pelatih, maupun usaha penghayatan yang dilakukan oleh aktor pantomim. Hal ini sesuai dengan fungsi embodiment yang dilakukan secara personal maupun komunal.

\section{Daftar Pustaka}

Allen Ness S A (2004) Being a body in a cultural way: Understanding the cultural in the embodiment of dance. In Thomas, H. dan Ahmed, J (ed). Cultual Bodies Ethnography and Theory. Oxford, UK: Blackwell Publishing. 123-144.

Atkinson P (2006) Opera and the embodiment of performance. In Waskul D dan Vannini P (ed). Body/Embodiment Symbolic Interaction and the Sociology of the Body. Burlington, USA: Ashgate Publishing Company. 95-108.

Iswantara N (2004) Sri Murtono: Teater tak pernah usai. Semarang: Intra Pustaka Utama.

Simatupang L (2013) Pergelaran sebuah mozaik penelitian seni-budaya. Yogyakarta: Jalasutra. 
Febrianto: "Penubuhan mimer dalam proses kreatif pertunjukan pantomim"

Soedarsono RM (1998) Seni pertunjukan Indonesia di era globalisasi. Jakarta: Dirjen Pendidikan Tinggi Departemen Pendidikan dan Kebudayaan.

Suhariyadi (2014) Dramaturgi. Sukodadi, Lamongan: CV Pustaka Ilalang Grup.

Wainwright S P dan Turner BS (2004) Narratives of embodiment: Body, aging, and career in royal balet dancers. Thomas $\mathrm{H}$ dan Ahmed J (ed). Cultural Bodies Ethnography and Theory. Oxford, UK: Blackwell Publishing. 98-120.

Waskul D dan Vannini P (2006) Body/embodiment symbolic Interaction and sociology of the body. Burlington, USA: Ashgate Publishing Company. 3-8. 